\title{
Antenatal Betamethasone Changes Cord Blood Monocyte Responses to Endotoxin in Preterm Lambs
}

\author{
BORIS W. KRAMER, MACHIKO IKEGAMI, TIMOTHY J.M. MOSS, ILIAS NITSOS, \\ JOHN P. NEWNHAM, AND ALAN H. JOBE
}

\begin{abstract}
University Children's Hospital, 97080 Würzburg, Germany [B.W.K.], Division of Pulmonary Biology, Cincinnati Children's Hospital Medical Center, Cincinnati, Ohio 45229, U.S.A. [M.I., A.H.J.], and School of Women's and Infants' Health, The University of Western Australia, Crawley, Western Australia 6009, Australia [T.J.M.M., I.N., J.P.N.]
\end{abstract}

\section{ABSTRACT}

$\mu \mathrm{mol}$ at $5 \mathrm{~h}, 8.7 \pm 2.9 \mu \mathrm{mol}$ at $24 \mathrm{~h}$, and $4.1 \pm 1.9 \mu \mathrm{mol}$ at $48 \mathrm{~h}$ versus $16.4 \pm 3.6 \mu \mathrm{mol}$ in control animals; at $7 \mathrm{~d}$, the hydrogen peroxide production increased to $74.3 \pm 19.7 \mu \mathrm{mol}(p<0.05$, per $10^{6}$ monocytes). IL-6 production was reduced at $15 \mathrm{~h}$ after maternal betamethasone but at no other time point. Maternal betamethasone initially suppressed several fetal monocyte functions, however, at $7 \mathrm{~d}$, measurements of initiation and resolution of inflammation were increased to levels similar to monocytes from adult sheep. The time-dependent changes in maternal betamethasone modulation of the responses of fetal monocytes may influence immune function of the preterm lamb after delivery.

(Pediatr Res 55: 764-768, 2004)

\section{Abbreviations}

BPD, bronchopulmonary dysplasia

GA, gestational age
Corticosteroids are potent modulators of fetal development, and antenatal corticosteroids are routinely used to decrease morbidity and mortality after preterm birth by inducing lung maturation (1). However, corticosteroids also are potent acute suppressors of immune/inflammatory responses (2). Fetal plasma corticosteroid levels are about $30 \%$ of the maternal levels after antenatal treatment with betamethasone (3). Fetal plasma corticosteroid concentrations decline rapidly within $4 \mathrm{~h}$ after maternal treatment with betamethasone (4). The effects of corticosteroids and their metabolites on fetal immune cells in vivo are poorly understood. In vitro exposure of fetal immune cells to corticosteroids acutely alters functions such as cell proliferation, apoptosis, phagocytosis, production of colony-

Received June 10, 2003; accepted November 20, 2003.

Correspondence: Boris W. Kramer, M.D., University Children's Hospital, Josef-Schneider-Str.

2, 97080 Würzburg, Germany; e-mail: kramer_b@kinderklinik.uni.wurgburg.de

Supported by grants HL-65397 and HD-12714 from the National Institutes of Health.

DOI: 10.1203/01.PDR.0000120678.72485.19 stimulating factors, and anti-inflammatory cytokine production (5-9). We have previously used cord blood-derived monocytes to study agents in vitro that are frequently used in the treatment of pulmonary inflammation in preterm infants (10). Similar suppressive effects on fetal immune cell function also occur after maternal corticosteroid treatments in vivo, and examples are decreased granulocyte chemokines and decreased lymphocyte numbers $(11,12)$. In contrast, Kavelaars et al. (11), also found enhanced natural killer cell activity in cord blood after antenatal corticosteroid exposure. The few evaluations of immune cell responses after maternal corticosteroid treatments did not control for the time interval from corticosteroid exposure to delivery. Because corticosteroids cause both immunosuppression and maturation, we hypothesized that the responses of fetal cord monocytes would change with time after maternal corticosteroid treatment. An initial suppression might be followed by a functional change that could represent reprogramming that might alter subsequent immune responses. 
Therefore, we exposed fetal sheep to a maternal corticosteroid treatment for time intervals from $15 \mathrm{~h}$ to $7 \mathrm{~d}$. We evaluated fetal blood monocytes for phagocytosis of Escherichia coli, responses to endotoxin exposure by hydrogen peroxide production, and IL-6 production as the marker for fetal inflammatory response syndrome (13). The resolution of inflammation was tested by phagocytosis of apoptotic neutrophils.

\section{METHODS}

Animals. The animal component of the study was performed in Western Australia, as approved by the animal care and use committees of Cincinnati Children's Hospital Medical Center (Cincinnati, OH, U.S.A.) and the Western Australian Department of Agriculture. Lung development in sheep at $124 \mathrm{~d}$ GA is in the saccular phase corresponding to human fetuses at 26-29 wk of gestation (14). A single dose of $0.5 \mathrm{mg} / \mathrm{kg}$ betamethasone induces lung maturation in preterm sheep (15). Injections were given at different gestational ages to deliver all animals at $124 \mathrm{~d}$ GA. Date-bred Merino ewes with singleton fetuses were randomly assigned in groups of five to nine animals. A single dose of maternal betamethasone $(0.5 \mathrm{mg} / \mathrm{kg}$ intramuscularly) (Celestone Chronodose, Schering-Plough Pty. Ltd., Baulkham Hills, NSW, Australia) was given 15 h, 1 d, $2 \mathrm{~d}$, or $7 \mathrm{~d}$ before preterm delivery at $124 \mathrm{~d}$ GA. Control animals were concurrently given $0.9 \%$ saline injections at $15 \mathrm{~h}$, $1 \mathrm{~d}, 2 \mathrm{~d}$, or $7 \mathrm{~d}$ before delivery at $124 \mathrm{~d}$ GA.

Cell isolation and culture. Cord blood was collected from an umbilical artery from each fetus at the time of cesarean section. Jugular venous blood from healthy adult ewes also was collected $(n=10)$. Complete white blood counts were performed on umbilical cord blood samples. Fetal plasma cortisol concentrations were determined with a commercial RIA (Valeant Pharmaceuticals International, Costa Mesa, CA, U.S.A.). The blood was diluted with PBS and layered onto a Percoll gradient (Amersham Pharmacia Biotech, Inc., Piscataway, NJ, U.S.A.) (16). After centrifugation for $40 \mathrm{~min}$ at 400 $\times g$ at $20^{\circ} \mathrm{C}$, the mononuclear cells and granulocytes were recovered, washed twice with $\mathrm{PBS}$ at $4^{\circ} \mathrm{C}$, centrifuged for 5 min at $400 \times g$ at $4^{\circ} \mathrm{C}$, and resuspended in culture media (Dulbecco's modified minimal media) supplemented with 10\% heat-inactivated FCS (Sigma Chemical, St. Louis, MO, U.S.A.). Cells were counted using trypan blue to evaluate viability and then plated in culture dishes. After incubation at $37^{\circ} \mathrm{C}$ for $2 \mathrm{~h}$, nonadherent cells were removed and plates were washed twice with PBS. To estimate the number of monocytes, cells were scraped from the culture dishes, and differential cell counts were performed on cytospin preparations stained with DiffQuick (Baxter Healthcare Corp., McGraw Park, IL, U.S.A.). The adherent cell population was $90 \pm 3 \%$ monocytes for all treatment and control groups. Monocytes in other culture dishes were cultured overnight, and the experiments were done the next day after about $16 \mathrm{~h}$ in culture.

Phagocytosis of E. coli. After overnight incubation, monocytes were washed with PBS and new culture media was added. Monocytes were exposed to FITC-labeled E. coli (Sigma Chemical) for $6 \mathrm{~h}$. The monocytes were resuspended, washed three times with PBS, and divided into two equal aliquots. The total bound and ingested bacteria were measured by flow cytometry. Trypan blue $(1.25 \mathrm{mg} / \mathrm{mL})$ was added to one aliquot to measure ingested bacteria only. Trypan blue quenches fluorescence of FITC-labeled E. coli that are surface bound but not ingested (17).

Hydrogen peroxide production and IL-6 concentration. After overnight incubation, monocytes were washed with PBS and new culture media was added. After $6 \mathrm{~h}$ incubation with endotoxin (100 ng/mL, E. coli, serotype 055:B5, Sigma Chemical) [a dose that induces a robust response in preterm monocytes (10)], monocytes were scraped from the culture dish, counted, and assessed for viability with trypan blue. Production of hydrogen peroxide by $1 \times 10^{6}$ monocytes was measured with an assay based on the oxidation of ferrous iron $\left(\mathrm{Fe}^{2+}\right)$ to ferric iron $\left(\mathrm{Fe}^{3+}\right)$ by hydrogen peroxide under acidic conditions (Bioxytech $\mathrm{H}_{2} \mathrm{O}_{2}-560$ assay, OXIS International, Portland, OR, U.S.A.). Control samples were exposed to saline instead of endotoxin and were included in all experiments (10). Concentrations of IL-6 were determined in the supernatant of endotoxin-stimulated monocytes by an ovine-specific ELISA as previously described (18).

Induction of apoptosis and phagocytosis of apoptotic neutrophils. Neutrophils were isolated from adult animals. Contaminating erythrocytes were removed by osmotic lysis (16). Apoptosis in neutrophils was induced by $10 \mathrm{~min}$ of UV radiation followed by $3 \mathrm{~h}$ of culture (19). Apoptosis and necrosis were quantified by flow cytometry. Apoptotic cells were stained with fluorescent-labeled annexin V. Necrotic cells were stained with proprium iodide and the relative cell populations counted by flow cytometry (20). After overnight incubation, monocytes were washed with PBS and new culture media was added. Phagocytosis of apoptotic neutrophils was tested by adding $2 \times 10^{6} / \mathrm{mL}$ apoptotic neutrophils to the adherent monocytes in culture dishes (19). The monocytes and apoptotic neutrophils were incubated for $6 \mathrm{~h}$ at $37^{\circ} \mathrm{C}$ and washed with ice-cold PBS containing 0.5 mM EDTA. Cells in the culture dishes were fixed and stained with hematoxylin and eosin. Phagocytosis was evaluated by counting apoptotic vesicles in 300 monocytes per well (10).

Data analysis. Results are presented as mean \pm SEM. Comparisons between betamethasone-treated groups and untreated controls were by ANOVA with Student-NewmanKeuls tests used for posthoc analyses. Results also were compared with monocytes from healthy sheep. Statistical significance was accepted at $p<0.05$.

\section{RESULTS}

Monocyte counts in complete white blood counts and plasma cortisol concentrations. Maternal betamethasone did not change the number of monocytes in umbilical cord blood in preterm lambs (Table 1). The fetal plasma cortisol concentrations were not different after maternal treatment with betamethasone (Table 1).

Phagocytosis. Although phagocytosis of E. coli by blood monocytes from adult sheep tended to be higher than for fetal sheep at $124 \mathrm{~d}$ gestation, the difference was not significant (Fig. 1A). Maternal betamethasone treatments had no effect on the 
Table 1. Number of monocytes in cord blood and cortisol concentration in cord plasma

\begin{tabular}{|c|c|c|c|c|c|}
\hline & \multirow[b]{2}{*}{ Control } & \multicolumn{4}{|c|}{ Time after maternal betamethasone treatment } \\
\hline & & $15 \mathrm{~h}$ & $1 \mathrm{~d}$ & $2 \mathrm{~d}$ & $7 \mathrm{~d}$ \\
\hline Monocytes (per $\mu \mathrm{L}$ ) & $60 \pm 15$ & $35 \pm 25$ & $95 \pm 35$ & $120 \pm 40$ & $70 \pm 20$ \\
\hline
\end{tabular}
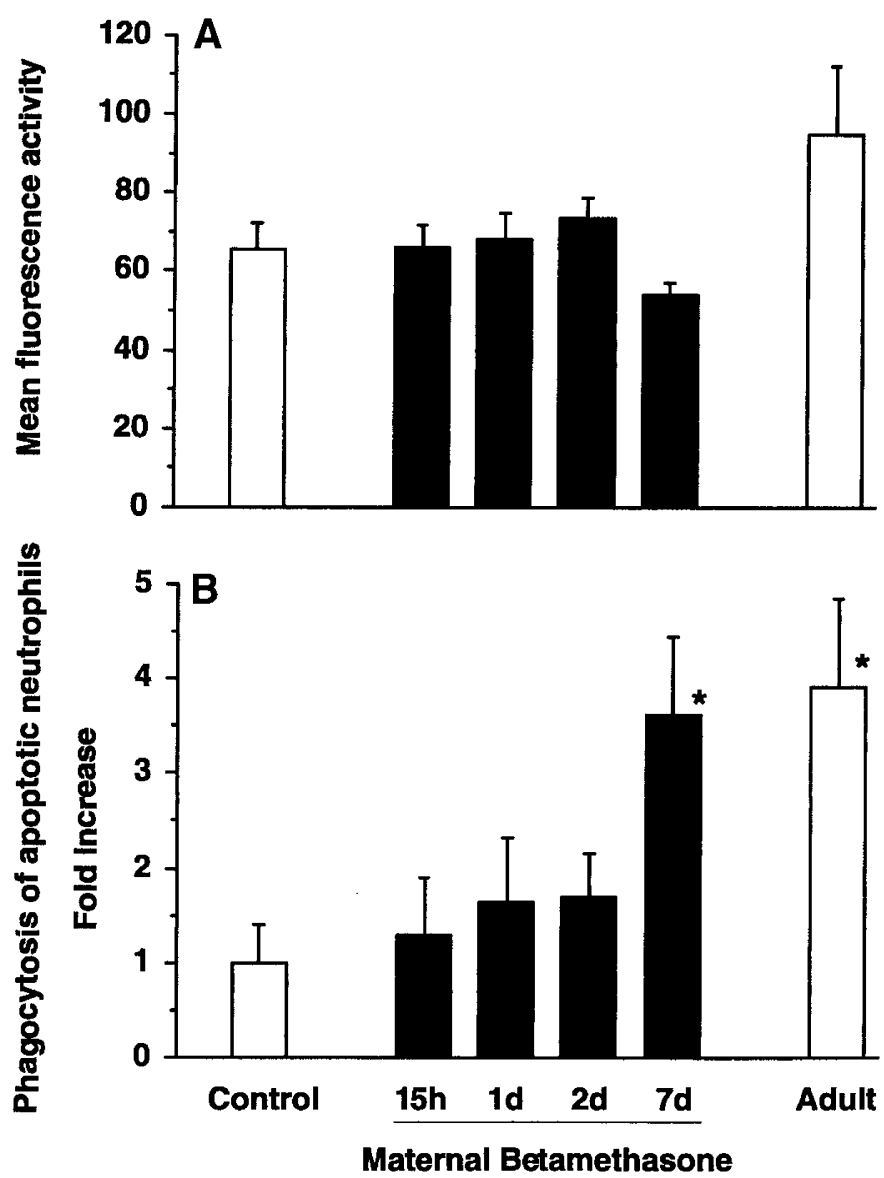

Figure 1. (A) Phagocytosis of fluorescent-labeled bacteria was not different between monocytes from preterm lambs $(n=9)$ and monocytes from adult sheep $(n=10)$. Phagocytosis was not changed by exposure to maternal betamethasone. The number of measurements were at $15 \mathrm{~h} n=5$, at $1 \mathrm{~d} n=$ 6 , at $2 \mathrm{~d} n=6$, and $7 \mathrm{~d} n=6$. (B) Phagocytosis of apoptotic neutrophils was quantified by counting apoptotic vesicles in monocytes. Results are shown as fold increase over control animals, which were set to 1 . The low phagocytosis in monocytes from preterm lambs increased $7 \mathrm{~d}$ after maternal betamethasone to a value similar to the phagocytosis of monocytes from adult sheep $(p<0.05$ vs control).

phagocytosis of $E$. coli by monocytes from the preterm lamb. However, phagocytosis of apoptotic neutrophils was increased in blood monocytes from adult sheep relative to the preterm lamb (Fig. 1B). The maternal betamethasone treatment did not change apoptotic neutrophil phagocytosis at $15 \mathrm{~h}, 1 \mathrm{~d}$, or $2 \mathrm{~d}$. However, phagocytosis increased 3 -fold to be similar to the value in the adult monocytes $7 \mathrm{~d}$ after maternal betamethasone treatment.

Endotoxin-stimulated $\mathrm{H}_{2} \mathrm{O}_{2}$ and IL-6 production. Monocyte activation was assessed after exposure of monocytes in culture to endotoxin. Blood monocytes from adult sheep produced about three times more $\mathrm{H}_{2} \mathrm{O}_{2}$ in response to endotoxin than did the monocytes from the preterm lambs (Fig. 2).

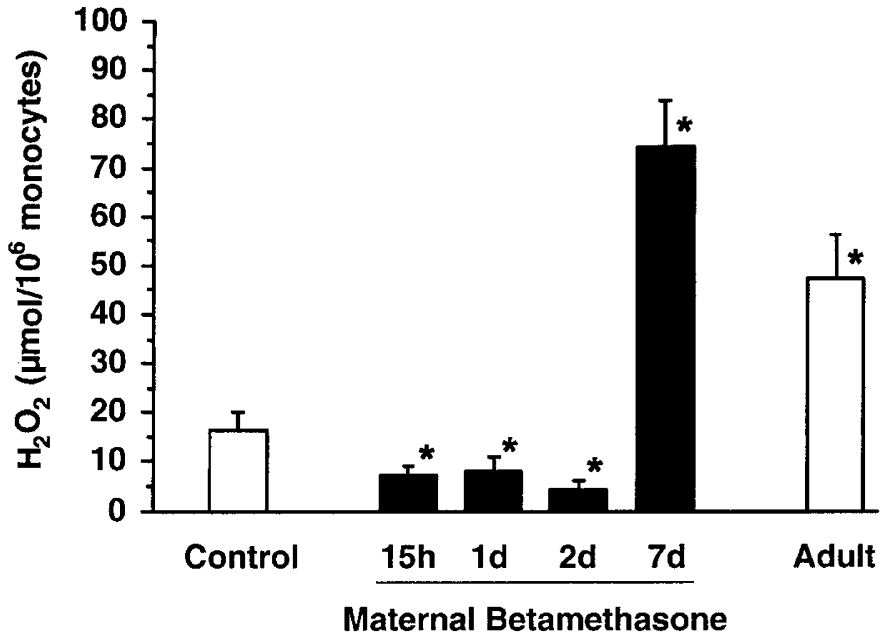

Figure 2. Production of hydrogen peroxide after stimulation with $100 \mathrm{ng} / \mathrm{mL}$ endotoxin. Production of hydrogen peroxide was lower in monocytes from preterm animals than in monocytes from adult sheep. Exposure to maternal betamethasone decreased production of hydrogen peroxide at $15 \mathrm{~h}, 1 \mathrm{~d}$, and $2 \mathrm{~d}$. At $7 \mathrm{~d}$ after maternal betamethasone exposure, hydrogen peroxide production was increased in monocytes from preterm animals and not different from monocytes from adult sheep ( $p<0.05 v s$ control)

Maternal betamethasone treatment suppressed $\mathrm{H}_{2} \mathrm{O}_{2}$ production at $15 \mathrm{~h}, 1 \mathrm{~d}$, and $2 \mathrm{~d}$. However, $7 \mathrm{~d}$ after the maternal treatment, the $\mathrm{H}_{2} \mathrm{O}_{2}$ production was similar to that of adult monocytes. IL- 6 secretion by the cultured monocytes was about 2.5 times higher for adult monocytes than for preterm monocytes (Fig. 3). Maternal betamethasone treatment initially

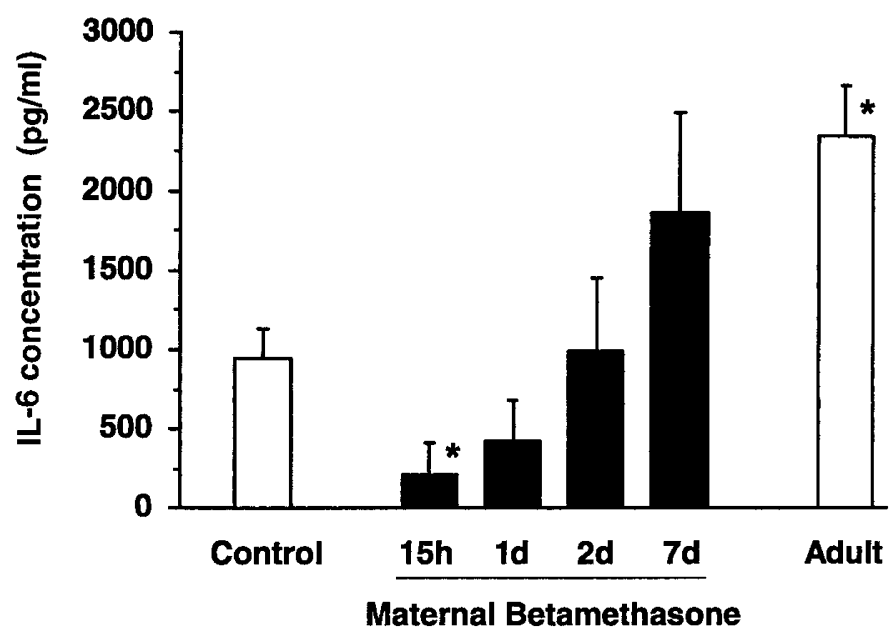

Figure 3. Concentrations of IL-6 in culture media after stimulation with endotoxin. Concentrations were determined by ELISA. IL-6 concentrations were lower in monocytes from preterm sheep than in monocytes from adult sheep. Exposure to maternal betamethasone reduced IL- 6 concentrations after $15 \mathrm{~h}(p<0.05$ vs control). 
suppressed IL-6 after a $15 \mathrm{~h}$ exposure, and IL-6 was qualitatively increased to a value similar to the adult cell response at $7 \mathrm{~d}$.

\section{DISCUSSION}

We used a sheep model that allowed us to evaluate monocyte responses to antenatal corticosteroid exposures that are similar in dose and duration to the clinical use of maternal corticosteroid treatments. We and others have demonstrated that monocytes and macrophages from preterm subjects have multiple differences in responses from the adult blood monocytes $(10,21-25)$. The effects of antenatal corticosteroids on human monocytes have not been evaluated in detail, although corticosteroids can acutely modulate inflammatory responses when cord blood monocytes are exposed to corticosteroids in culture $(7,26,27)$. As would be anticipated from antiinflammatory effects, antenatal betamethasone suppressed $\mathrm{H}_{2} \mathrm{O}_{2}$ production for $2 \mathrm{~d}$ and IL- 6 production at $15 \mathrm{~h}$. The interesting responses were the augmented phagocytosis of apoptotic neutrophils, the increased $\mathrm{H}_{2} \mathrm{O}_{2}$, and the trend to increase IL- 6 secretion by the monocytes from the $7 \mathrm{~d}$ corticosteroid group. These monocytes have responses that are similar to monocytes from the adult animal. With the limited information that we have, it is not clear what these changes in responses are. It is too simplistic to say that the monocytes were initially suppressed and then matured by the corticosteroid because we do not know the fate or persistence of the changed responses. However, at least for an interval of $7 \mathrm{~d}$, a single corticosteroid exposure reprogrammed the responses of the fetal monocytes.

This finding adds to other effects of maternal corticosteroids on fetal immune cells. Several deficits in immune function have been reported after maternal corticosteroid treatment, such as decreased neutrophil chemotaxis (28) and decreased absolute numbers and proliferation of fetal lymphocytes with a reduced production of IL-2 $(12,29)$. This effect was not limited to the fetus but affected maternal lymphocytes as well (29). However, maternal corticosteroid effects are not exclusively immunosuppressive inasmuch as maternal treatment increased the activity of natural killer cells in preterm infants (11).

The effects of altered monocyte function in the fetus will depend on how other components of the immune/inflammatory system are altered by the antenatal corticosteroid exposure. There are several target organs for adverse immune/ inflammatory effects in the preterm infant. The brain may be injured as a consequence of a systemic inflammatory response (30). BPD is associated with chorioamnionitis and fetal infection and antenatal corticosteroids suppress alveolar septation in the developing lung (31). Assuming that blood monocytes populate the fetal lung and differentiate to become alveolar macrophages $(10,32,33)$, altering monocyte function to be more pro-inflammatory by increasing the capacity for $\mathrm{H}_{2} \mathrm{O}_{2}$ and IL-6 production could be detrimental. In a previous study, we used cord blood-derived monocytes to study agents in vitro that are used in the treatment of pulmonary disease in preterm infants (10). The phagocytosis of apoptotic cells by monocytes was increased in the presence of both surfactant proteins and phospholipids. As an example of interactive phenomena resulting in the potential for increased lung injury, we reported that fetuses exposed to intra-amniotic endotoxin $30 \mathrm{~d}$ before preterm delivery had increased numbers of monocytes in alveolar washes and more pro-inflammatory cytokine mRNA after mechanical ventilation than did control lambs (34). This experiment demonstrates that a fetal exposure can change a postnatal immune/inflammatory response. Antenatal corticosteroids decrease respiratory distress syndrome but do not decrease BPD (1). In the meta-analysis of Crowley (1), the relative risk of BPD after antenatal steroids was 1.38 (95\% confidence interval, 0.90-2.11) which was a trend toward increasing the risk of BPD. This unanticipated outcome has been explained by survival of the smaller and more marginal infants at highest risk for BPD. Banks et al. observed severe respiratory failure in some preterm infants after repetitive courses of antenatal corticosteroids (35). Perhaps antenatal corticosteroids can augment an inflammatory response to a second stimulus after birth and contribute to the development of BPD in some infants.

This concept of interacting signals amplifying a fetal response also has been demonstrated by the simultaneous exposure of fetal sheep to maternal corticosteroids and intraamniotic endotoxin. Intra-amniotic endotoxin is a model of the chronic chorioamnionitis that is frequently associated with preterm birth in humans (36). Intra-amniotic endotoxin causes chorioamnionitis and lung inflammation in fetal sheep $(15,18$, 37). Maternal corticosteroids suppress the acute inflammation for about $3 \mathrm{~d}$ after the intra-amniotic endotoxin, but there is a late inflammatory response that persists for $5-15 \mathrm{~d}$ (38). The late inflammation that follows the initial corticosteroid-induced suppression of inflammation may result in part from priming of the immature inflammatory response by corticosteroids.

We found that maternal corticosteroid had a biphasic immunomodulatory effect on blood monocytes in the fetal sheepsuppression of function followed by augmented function. We speculate that this augmented function represents reprogramming that could have long-term effects on subsequent immune responses in fetal and later life.

\section{REFERENCES}

1. Crowley P 2003 Prophylactic corticosteroids for preterm birth. Cochrane Database Syst Rev 2:CD000065

2. Schacke H, Docke WD, Asadullah K 2002 Mechanisms involved in the side effects of glucocorticoids. Pharmacol Ther 96:23-43

3. Jobe AH 2001 Glucocorticoids, inflammation and the perinatal lung. Semin Neonatol 6:331-342

4. Berry LM, Polk DH, Ikegami M, Jobe AH, Padbury JF, Ervin MG 1997 Preterm newborn lamb renal and cardiovascular responses after fetal or maternal antenatal betamethasone. Am J Physiol 272:R1972-R1979

5. Bessler H, Kagazanov S, Punsky I, Sirota L 2001 Effect of dexamethasone on IL-10 and IL-12p40 production in newborns and adults. Biol Neonate 80:262-266

6. Schwarze J, Bartmann P 1994 Influence of dexamethasone on lymphocyte proliferation in whole blood cultures of neonates. Biol Neonate 65:295-301

7. Witek-Janusek L, Mathews HL 1999 Differential effects of glucocorticoids on colony stimulating factors produced by neonatal mononuclear cells. Pediatr Res 45:224-229

8. Schelonka RL, Infante AJ 1998 Neonatal immunology. Semin Perinatol 22:2-14

9. Caudle MR, Harbert GMJ, Singhas CA 1981 Effect of betamethasone on fetal macrophage function: depression of adherence of immunoglobulin-coated red blood cells. Am J Reprod Immunol 1:182-184

10. Kramer BW, Jobe AH, Ikegami M 2003 Monocyte function in preterm, near term and adult sheep. Pediatr Res 54:52-57

11. Kavelaars A, van der Pompe G, Bakker JM, van Hasselt PM, Cats B, Visser GH, Heijnen CJ 1999 Altered immune function in human newborns after prenatal administration of betamethasone: enhanced natural killer cell activity and decreased $\mathrm{T}$ cell proliferation in cord blood. Pediatr Res 45:306-312 
12. Chabra S, Cottrill C, Rayens MK, Cross K, Lipke D, Bruce M 1998 Lymphocyte subsets in cord blood of preterm infants: effect of antenatal steroids. Biol Neonate 74:200-207

13. Yoon BH, Romero R, Kim KS, Park JS, Ki SH, Kim BI, Jun JK 1999 A systemic fetal inflammatory response and the development of bronchopulmonary dysplasia. Am J Obstet Gynecol 179:1254-1260

14. Pringle KC 1986 Human fetal lung development and related animals models. Clin Obstet Gynecol 29:502-513

15. Jobe AH, Newnham JP, Willet KE, Sly P, Ervin MG, Bachurski C, Possmayer F, Hallman M, Ikegami M 2000 Antenatal endotoxin and glucocorticoid effects on the lungs of preterm lambs. Am J Obstet Gynecol 182:401-408

16. Kanof ME, Smith PD, Zola H 1996 Separation of peripheral blood mononuclear cells In: Coligan JE, Kruisbeek AM, Margulies DH, Shevach EM, Strober W (eds) Current Protocols in Immunology. Wiley-Interscience, New York, pp 7.1.1-7.1.7

17. Hed J, Hallden G, Johansson SG, Larsson P 1989 Quantitative rather than qualitative differences between monocytes with respect to IgE Fc receptor expression as studied by flow cytofluorometry. Int Arch Allergy Appl Immunol 88:408-411

18. Kramer BW, Moss TJ, Willet KE, Newnham JP, Sly PD, Kallapur SG, Ikegami M, Jobe AH 2001 Dose and time response after intraamniotic endotoxin in preterm lambs. Am J Respir Crit Care Med 164:982-988

19. Hu B, Sonstein J, Christensen PJ, Punturieri A, Curtis JL 2000 Deficient in vitro and in vivo phagocytosis of apoptotic $\mathrm{T}$ cells by resident murine alveolar macrophages. J Immunol 165:2124-2133

20. Vermes I, Haanen C, Steffens-Nakken H, Reutelingsperger C 1995 A novel assay for apoptosis. Flow cytometry detection of phosphatidylserine expression on early apoptotic cells using fluorescin labeled Annexin V. J Immunol Methods $184: 39-51$

21. Marshall-Clarke S, Reen D, Tasker L, Hassan J 2000 Neonatal immunity: how well has it grown up? Immunol Today 21:35-41

22. Weiss RA, Chanana AD, Joel DD 1986 Postnatal maturation of pulmonary antimicrobial defense mechanisms in conventional and germ-free lambs. Pediatr Res 20:496-504

23. Zeligs BJ, Nerurkar LS, Bellanti JA, Zeligs JD 1977 Maturation of the rabbit alveola macrophage during animal development. I. Perinatal influx into alveoli and ultrastructural differentiation. Pediatr Res 11:197-208

24. Nerurkar LS, Zeligs BJ, Bellanti JA 1977 Maturation of the rabbit alveolar macrophage during animal development. II. Biochemical and enzymatic studies. Pediatr Res 11:1202-1207
25. Zeligs BJ, Nerurkar LS, Bellanti JA 1977 Maturation of the rabbit alveolar macrophage during animal development. III. Phagocytic and bactericidal functions. Pediat Res 11:1208-1211

26. Schultz C, Rott C, Temming P, Schlenke P, Möller JC, Bucsky P 2002 Enhanced interleukin-6 and interleukin-8 synthesis in term and preterm infants. Pediatr Res 51:317-322

27. Dembinski J, Behrendt D, Martini R, Heep A, Bartmann P 2003 Modulation of proand anti-inflammatory cytokine production in very preterm infants. Cytokine 21:200206

28. Fuenfer MM, Herson VC, Raye JR, Woronick CL, Eisenfeld L, Ingardia CJ, Block CF, Krause PJ 1987 The effect of betamethasone on neonatal neutrophil chemotaxis. Pediatr Res 22:150-153

29. Murthy KK, Moya FR 1994 Effect of betamethasone on maternal, fetal and neonatal rat cellular immunity. Early Hum Dev 36:1-11

30. Nelson KB, Dambrosia JM, Grether JK, Phillips TM 1998 Neonatal cytokines and coagulation factors in children with cerebral palsy. Ann Neurol 44:665-675

31. Jobe AH, Ikegami M 2001 Antenatal infection/inflammation and postnatal lung maturation and injury. Respir Res 2:27-32

32. Jacobs RF, Wilson CB, Palmer S, Springmeyer SC, Henderson WR, Glover DM, Kessler Jr DL, Murphy JH, Hughes JP, van Belle G, Chi EY, Hodson WA 1985 Factors related to the appearance of alveolar macrophages in the developing lung. Am Rev Respir Dis 131:548-553

33. Radzun HJ, Parwaresch MR, Kreipe H 1983 Monocytic origin of human alveolar macrophages. J Histochem Cytochem 31:318-324

34. Ikegami M, Jobe AH 2002 Postnatal lung inflammation increased by ventilation of preterm lambs exposed antenatally to Escherichia coli endotoxin. Pediatr Res 52:356-362

35. Banks BA, Cnaan A, Morgan MA, Parer JT, Merrill JD, Ballard PL, Ballard RA 1999 Multiple courses of antenatal corticosteroids and outcome of premature neonates. Am J Obstet Gynecol 181:709-717

36. Goldenberg RL, Hauth JC, Andrews WW 2000 Intrauterine infection and preterm delivery. N Engl J Med 342:1500-1507

37. Kallapur SG, Willet KE, Jobe AH, Ikegami M, Bachurski CJ 2001 Intra-amniotic endotoxin: chorioamnionitis precedes lung maturation in preterm lambs. Am J Physiol 280:L527-L536

38. Kallapur SG, Kramer BW, Moss TJ, Newnham JP, Jobe AH, Ikegami M, Bachurski CJ 2003 Maternal glucocorticoids increase endotoxin induced lung inflammation in preterm lambs. Am J Physiol 284:L633-L642 